\title{
Recommender System for Personalised Wellness Therapy
}

\author{
Thean Pheng Lim \\ School of Computer Sciences \\ Universiti Sains Malaysia \\ 11800 Penang, Malaysia
}

\author{
Wahidah Husain \\ School of Computer Sciences \\ Universiti Sains Malaysia \\ 11800 Penang, Malaysia
}

\author{
Nasriah Zakaria \\ School of Computer Sciences \\ Universiti Sains Malaysia \\ 11800 Penang, Malaysia
}

\begin{abstract}
- rising costs and risks in health care have shifted the preference of individuals from health treatment to disease prevention. This prevention treatment is known as wellness. In recent years, the Internet has become a popular place for wellness-conscious users to search for wellness-related information and solutions. As the user community becomes more wellness conscious, service improvement is needed to help users find relevant personalised wellness solutions. Due to rapid development in the wellness market, users value convenient access to wellness services. Most wellness websites reflect common health informatics approaches; these amount to more than 70,000 sites worldwide. Thus, the wellness industry should improve its Internet services in order to provide better and more convenient customer service. This paper discusses the development of a wellness recommender system that would help users find and adapt suitable personalised wellness therapy treatments based on their individual needs. This paper introduces new approaches that enhance the convenience and quality of wellness information delivery on the Internet. The wellness recommendation task is performed using an Artificial Intelligence technique of hybrid case-based reasoning (HCBR). HCBR solves users' current wellness problems by applying solutions from similar cases in the past. From the evaluation results for our prototype wellness recommendation system, we conclude that wellness consultants are using consistent wellness knowledge to recommend solutions for sample wellness cases generated through an online consultation form. Thus, the proposed model can be integrated into wellness websites to enable users to search for suitable personalized wellness therapy treatment based on their health condition.
\end{abstract}

Keywords-recommender system; rule-based reasoning; casebased reasoning; Wellness

\section{INTRODUCTION}

The concept of health has shifted from treatment of disease to prevention of health problems $[1,2]$. As the online community has become more health conscious, improvement is needed to ensure accessibility, reliability and quality of wellness services on the Internet. Many people are turning to wellness websites for work-life balance and healthy lifestyle programmes to fulfil their wellness needs.

Research shows that there are more than 70,000 health informatics websites [3] and one recent study, found more than $54,700,000$ results in Google for the term "health assessment tools" [4]. This excess of information has created complications in searching for wellness solutions on wellness websites.
A study on the reliability of health information provided by websites shows inconsistent recommendations, for example in managing fever in children [5]. Inconsistent recommendations negatively affect the quality of health information on the web [6]. It can lead to actual or perceived untrustworthiness of web content, so that users have to navigate and filter to find credible information [7]. The user experiences wellness information overload, which causes uncertainty, confusion and distraction [8]. Furthermore, it is a challenge for users to select a suitable wellness therapy on the Internet since they are lacking in wellness and health understanding. For example, with limited knowledge about health, human anatomy and medical terminology, users may inaccurately describe their symptoms which may cause errors in diagnosis. Most wellness websites do not provide support or consultation for users of their wellness recommendations. Disclaimers on wellness websites frequently indicate that the solutions provided are not for wellness recommendation purposes $[9,10,11]$. Information and guidance provided on such websites are not verified by qualified wellness practitioners, and users may be confused if they follow the suggestions offered. Wellness websites should state clearly what users can get from their web services rather than frustrating them.

The purpose of this study is to design a wellness recommendation model that will suggest personalised wellness therapy or treatments to online users. The objective of the study is to find the best technique for matching users' wellness concerns with appropriate wellness therapy. This model will help to ensure the reliability of wellness recommendations proposed to users based on their current wellness conditions and constraints. At the end of the study, a field evaluation survey was carried out to ensure the reliability and suitability of the wellness solutions proposed by the recommender system.

\section{BACKGROUND STUDY}

This section reviews two recommender systems that are commonly used in e-commerce transactions: content-based filtering and collaborative filtering. The section also reviews two popular knowledge-based techniques that are currently implemented in the health care environment: case-based reasoning and rule-based reasoning.

\section{A. Recommender Systems}

In the modern knowledge era, the extensive number of applications available on the Internet make searching increasingly convenient for users. 
This is due to the introduction of recommender systems that filter unseen information, predict the preferences and needs of users [12], and make suggestions to them. Recommender systems are widely used in e-commerce to search for product information and assist customers in deciding what to buy [13]. A recommender system helps users navigate through a large information space to selective descriptions of items that they need [14]. Two common types of recommender system are content-based filtering and collaborative filtering [15].

Content-based filtering is based on similarity of content, such as previous successful transactions [16]. The general principle of the content-based approach is to identify common characteristics of a user's past choices and then recommend new items that share these characteristics [17]. Content-based recommender systems are a type of classifier system, and are related to machine learning research [14]. A user's profile in the system learns from feedback and responses provided by the user [18]. A content-based recommender system compares a user's profile of past selections with the information stored in the database, which is sorted according to similarity and ranked based on the user's known preferences. The content-based approach has several shortcomings. Most importantly, the system can only recommend based on a user's previous ratings; the system cannot recommend new items unless they are similar to previously-liked items [14]. The content-based recommender system is thus not ideal if the user is new to the system, because very little information is available to be compared. In such circumstances, it will negatively impact the effectiveness of the system's recommendations to the user.

On the other hand, collaborative filtering recommends items based on aggregated user preferences, which does not depend on similarity of item descriptions [19]. A collaborative recommender system recommends solutions based on what other similar users have liked. Users with similar preferences are grouped together and are called neighbours [20]. Amazon.com uses collaborative filtering to recommend books to its customers based on books that other similar customers have said that they liked [20]. Collaborative filtering also suffers from a few limitations. There is a significant delay in the rating process because recommendations are made based on preferences of similar users. If there are very few users, it will be harder to find groups of similar ones. Also, if the solution or item has not been rated by similar users, or the solution is very new, the recommender system will not propose the solution because there are not enough ratings to support the recommendation [21].

\section{B. Knowledge-based systems}

John McCarthy defined Artificial Intelligence (AI) as "the science and engineering of making intelligent machines." [22]. It is related to the activities of computers in understanding human intelligence. The central problems of AI include reasoning, learning, knowledge and communication, all of which are common and valuable to most industries [23]. Expert systems are a branch of AI that applies reasoning methodologies and domain-specific knowledge to make recommendations, just like a human expert would [24]. To enable this quick and reliable decision-making process, human experts' knowledge is converted to a knowledge-based system which can be queried for assistance. In the medical context, a physician can diagnose and suggest treatments for an illness despite the ambiguity of symptoms and wide range of medical problem faced by different individuals [25]. Therefore, a physician must use several different types of reasoning. In AI, the most frequently used knowledge-based reasoning techniques are rule-based reasoning (RBR) and case-based reasoning (CBR).

RBR uses "if-then-else" rule statements [26]. Rules are patterns, so the RBR engine searches for patterns in the rules that match patterns in the data. Problem solving becomes more complex if there are too many rules to match the pattern of data in the database [26]. The RBR system uses rule chaining and a combination of data and the system's justification capability to provide a solution to the users [27]. However, RBR lacks the ability to learn due to the difficulty of acquiring new expertise in pattern matching or new rules [28]. RBR also requires a user to take into account all the domain rules; in real life problem solving, the pressures of time restrict problem solvers from looking into large unmanageable rule sets to solve a problem [29]. Thus, RBR is an ideal approach for solving simple problems where not many rules exist.

The CBR approach is similar to human problem-solving behaviour. In CBR, the problem is solved based on experience gained by solving similar problems in the past [30]. CBR is a proven methodology that applies past solutions to solve new but similar problems [31]. The CBR cycle consists of four steps: retrieving previous cases from the case database, reusing a previous case to recommend a solution, revising a previous solution to match the current problem, and retaining new cases after a solution has been successfully found [32].

CBR is a useful alternative to RBR. In complex RBR systems, it is difficult to formulate situations with hard and fast rules due to the complexity of converting problem-solving knowledge due to incomplete problem specifications [30]. However, in CBR, if new knowledge is not available but solutions can be derived from old cases, then on the basis of past experiences, the problem can be solved [30]. CBR is not restricted only to reuse of past cases. It also has good learning capabilities, and its problem solving skills improve as new cases are solved and stored in the database [26]. In our preliminary research, we propose a CBR recommender model to solve users' wellness needs, as illustrated in Fig. 1.

When a new case is entered, the CBR system retrieves similar cases from its case database. The system reuses a solution from a previous case, if necessary adapting it for the new case. The proposed solution is revised to confirm the validity and reliability of the solution. Finally, the revised case will be stored in the case database so it can be used for solving new problems in the future.

\section{PRoposed ReCommender Model}

This section discusses the characteristics of the proposed hybrid case-based reasoning recommender system for wellness, and walks through a simulation of the recommender system using sample cases, of a paragraph. 


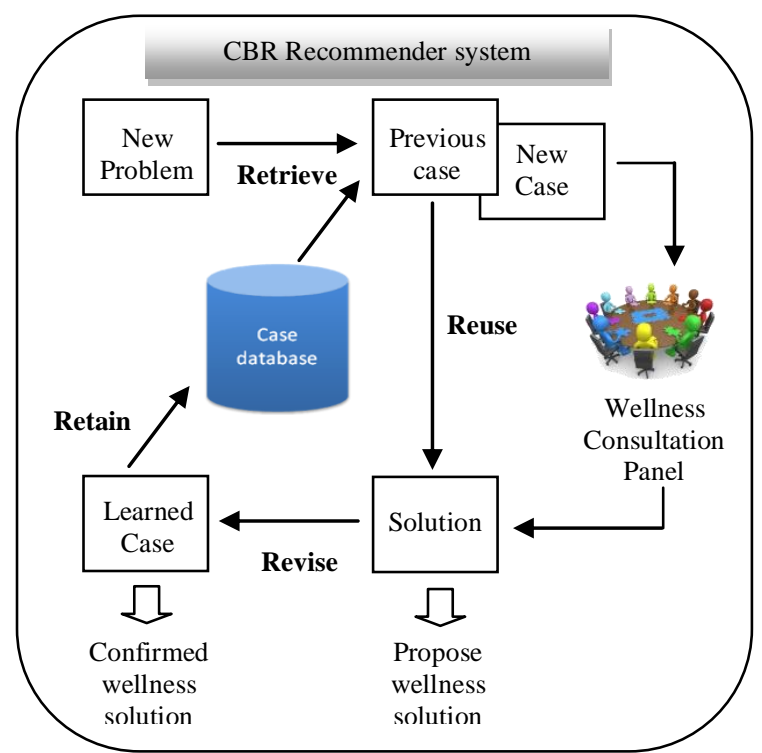

Fig. 1. Wellness recommender model using CBR [33]

Table 1 is a comparison of the advantages and disadvantages of RBR and CBR techniques.

TABLE I. COMPARISON OF RBR AND CBR

\begin{tabular}{|c|c|c|}
\hline & RBR & CBR \\
\hline Advantages & $\begin{array}{l}\text { - Each rule can be } \\
\text { interpreted as one unit of } \\
\text { knowledge. } \\
\text { - Knowledge is expressed } \\
\text { in the same format. } \\
\text { - Rules are a natural } \\
\text { format to express } \\
\text { knowledge. }\end{array}$ & $\begin{array}{l}- \text { Easy to acquire knowledge } \\
\text { from human experts. } \\
\text { - Provides model of } \\
\text { learning. } \\
\text { - Can distinguish different } \\
\text { problems and select } \\
\text { appropriate cases as } \\
\text { solution. }\end{array}$ \\
\hline $\begin{array}{l}\text { Dis- } \\
\text { advantages }\end{array}$ & $\begin{array}{l}\text { - Difficult to represent } \\
\text { informal knowledge. } \\
\text { - Rules obtained from } \\
\text { human experts tend to be } \\
\text { highly heuristic in nature. } \\
\text { - Relies only on the rules } \\
\text { and does not learn. } \\
\text { - Poor efficacy due to } \\
\text { repetition of previous } \\
\text { errors. }\end{array}$ & $\begin{array}{l}\text { - Large case database leads } \\
\text { to high search cost. } \\
\text { - Difficult to determine good } \\
\text { criteria in indexing cases } \\
\text { and matching similar cases. }\end{array}$ \\
\hline
\end{tabular}

\section{A. The hybrid matching technique}

In the preceding section, we discussed two types of knowledge-based systems: rule-based reasoning (RBR) and case-based reasoning (CBR). RBR and CBR each have their respective pros and cons.

A combination of CBR and RBR will benefit the system wherein RBR helps to speed the filtering process of CBR [30, 34]. The task of indexing cases in the case database is also handled efficiently by the RBR system [26, 35]. This complements the limitation of CBR to return too many similar cases when there are too many criteria for problem solving in a large case database [26]. Standard rules are acquired from wellness experts and can be applied to solve new problems [36].
Hybrid case-based reasoning (HCBR) is the best approach for a wellness recommender system [27, 29, 36]. HCBR uses a combination of CBR and RBR approaches. HCBR incorporates the advantages of RBR into a sub-system which helps to standardize the format of rules to be used in indexing and searching for similar cases. The panel of wellness experts can contribute to storing standard rules in the RBR sub-system even when there is no similar case in the case database. The RBR sub-system proposes solutions based on standard rules stated in the rule database. The CBR component of HCBR has the ability to learn from previous and new cases, which compensates for the drawback of the RBR system. Therefore, HCBR performs better than RBR alone in terms of accuracy of solution [36]. The matching task is performed using an artificial intelligence (AI) approach employing case-based reasoning [37]. Each case is a module of knowledge that contains structured information about a wellness problem and the appropriate therapy. A case is triggered by matching its relevant components to those in the problem submitted by users. Fig. 2 shows the process flow of the proposed HCBR wellness recommender system.

In making a wellness recommendation, HCBR will consider three alternatives when a new wellness problem is entered. First, the system checks for the same wellness case in the database. If it is present, the solution from that previous case is used to solve the current wellness problem. If no identical wellness case exists in the case database, the system attempts to match users' wellness concerns with similar cases in the database. Similar cases are sorted using rules, as indicated in the RBR sub-system; the system uses these rules to calculate the level of similarity among cases. If the value of the most-similar case is above the acceptance threshold, the solution of that case is proposed to the user. Finally, if there is no case whose similarity level exceeds the acceptance threshold, the system triggers the RBR sub-system to apply standard rules predetermined by the wellness experts.

\section{B. Simulation of Wellness Recommender Prototype}

Prototyping begins with the design of the wellness recommendation module. In this study, the purpose of the system prototype is to capture the intended design and simulate the appearance, process and surface texture of the wellness recommendation module. The user requirements for the wellness recommender prototype were gathered from in-depth interview sessions with wellness experts through the Delphi interview technique. Twelve experts from different areas of the wellness industry were interviewed, including spa and relaxation, reflexology, beauty and slimming, skin and body care, and fitness. After attaining consensus on the user requirements, the wellness recommender prototype was developed.

Three sample cases are stored in the recommender system case database for simulation and evaluation purposes. The three sample cases are shown in Fig. 3.

To complete the simulation process, we created a new case to represent a current problem faced by a user. This new case is shown in Fig. 4. 


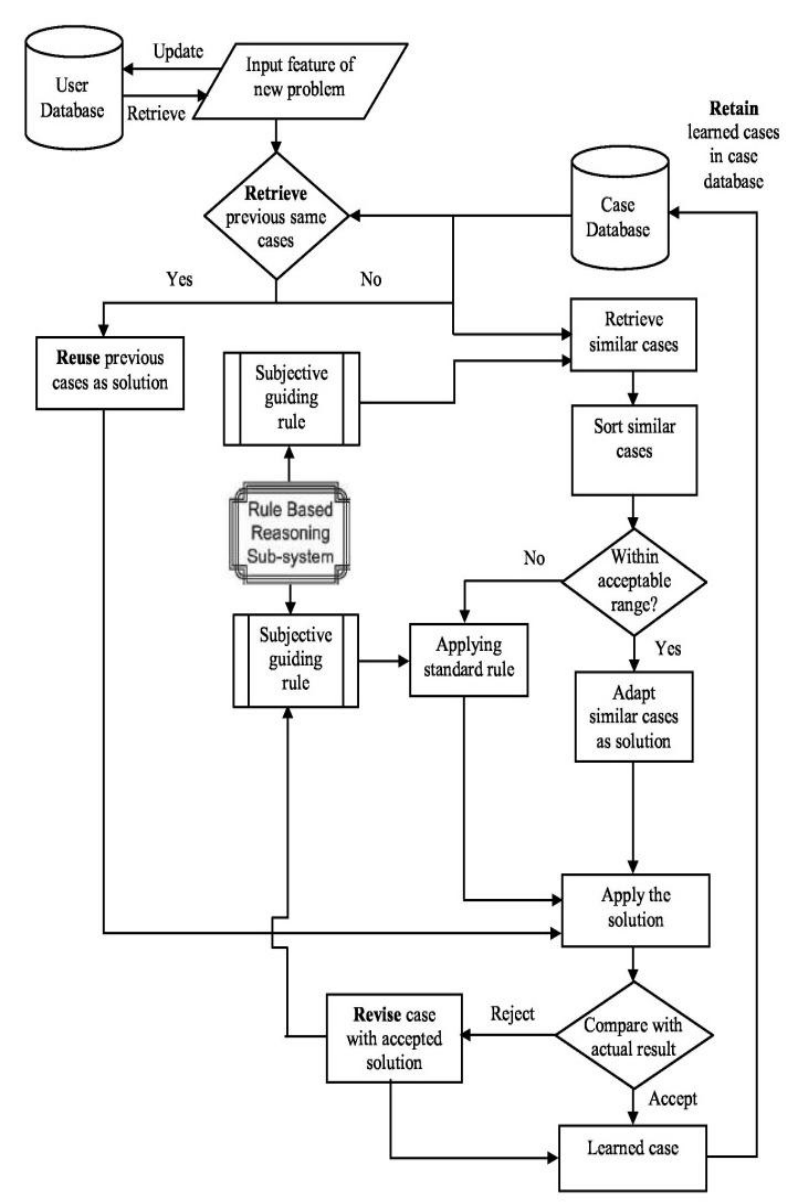

Fig. 2. Process flow of the proposed HCBR wellness recommender system

\begin{tabular}{|c|c|c|}
\hline SAMPLE 1 & SAMPLE 2 & SAMPLE 3 \\
\hline Age: 36 & Age: 25 & Age: 35 \\
\hline Sex: Male & Sex: Female & Sex: Female \\
\hline $\begin{array}{l}\text { Health Status: } \\
\text { High blood } \\
\text { pressure }\end{array}$ & $\begin{array}{l}\text { Health Status: } \\
\text { Insomnia }\end{array}$ & $\begin{array}{l}\text { Health Status: } \\
\text { High blood } \\
\text { pressure }\end{array}$ \\
\hline $\begin{array}{l}\text { Personal lifestyle: } \\
\text { Ability to relax } \\
\text { (poor), Stress level } \\
\text { (Work 10) }\end{array}$ & $\begin{array}{l}\text { Personal lifestyle: } \\
\text { Average sleeping } \\
\text { hours (3), Alcohol } \\
\text { (often) }\end{array}$ & $\begin{array}{l}\text { Personal lifestyle: } \\
\text { Skin Type (Dry), } \\
\text { Exercise (Never) }\end{array}$ \\
\hline $\begin{array}{l}\text { Wellness } \\
\text { concerns: Stress }\end{array}$ & $\begin{array}{l}\text { Wellness } \\
\text { concerns: Fatigue }\end{array}$ & $\begin{array}{l}\text { Wellness } \\
\text { concerns: Dry } \\
\text { Body (Arm, back, } \\
\text { chest) }\end{array}$ \\
\hline
\end{tabular}

Fig. 3. Sample cases stored in the wellness recommender prototype

\begin{tabular}{|l|}
\hline \multicolumn{1}{|c|}{ NEW CASE } \\
\hline Age: 27 \\
\hline Sex: Male \\
\hline Health Status: High blood pressure, Depression \\
\hline $\begin{array}{l}\text { Personal lifestyle: Ability to relax (poor), smoke } \\
\text { (often), Stress level (Work 10, Home 8) }\end{array}$ \\
\hline Wellness concerns: Stress, Anxiety \\
\hline
\end{tabular}

Fig. 4. New case entered into the wellness recommender prototype

After the new case is entered into the system, the recommender model first searches for an identical case in case database. In this simulation, no identical case appears in the database (neither Sample Case 1, 2 or 3 is the same as the new case). Therefore, the recommender system next searches for similar cases in the case database. The system carries out similarity computation using a weighted average nearest neighbour algorithm [33, 37]. This algorithm calculates the similarity between the score of the new case and that of the sample cases in the case database. The case with the highest $k$ score is selected as the most similar case and used to solve the new problem. The similarity between cases is quantified as a set of independent attributes [38], such as age, gender, lifestyle, previous health record and wellness concern. For each independent attribute, a metric is assigned to measure the similarity between two cases in terms of that attribute. For example, two attributes with the same value get the maximum similarity rating, while attributes whose values are greatly dissimilar get a low rating. The similarity between attributes has been predetermined by the wellness experts and stored as subjective guiding rules in the recommender system. The degree of similarity is expressed by a number between 0 (not at all similar) and 1 (very similar) [33, 37]. Fig.5 shows the similarity computation test between the new case and the three sample cases in case database.

The equation for similarity calculation using a weighted average near neighbour algorithm is:

$$
\left[1 / \sum_{F}^{N}\left(I_{F} * A_{F}\right)\right] * \sum_{X}^{N}\left(I_{X} * A_{X}\right)
$$

where $I_{F}$ and $I_{X}$ represent the importance of specific attributes while $A_{F}$ represents the full score for the specific attributes and $A_{X}$ represents the score given to the specific attributes.

Using this equation, the similarity computations for the new case and the three sample cases are as follows:

(Note: $5=$ high importance and $1=$ low importance) 


\begin{tabular}{|c|c|c|}
\hline NEW CASE & & SAMPLE 1 \\
\hline Age: $\mathbf{2 7}$ & 0.8 & Age: 36 \\
\hline Sex: Male & & Sex: Male \\
\hline $\begin{array}{r}\text { Health Status: High } \\
\text { blood pressure, } \\
\text { Depression }\end{array}$ & 0.9 & $\begin{array}{l}\text { Health Status: High } \\
\text { blood pressure }\end{array}$ \\
\hline $\begin{array}{r}\text { Personal lifestyle: Ability } \\
\text { to relax (poor), Smoke } \\
\text { (often), Stress level } \\
\text { (Work 10) }\end{array}$ & 0.9 & $\begin{array}{l}\text { Personal lifestyle: Ability } \\
\text { to relax (poor), Stress } \\
\text { level (Work 10) }\end{array}$ \\
\hline $\begin{array}{l}\text { Wellness concerns: } \\
\text { Stress, Anxiety }\end{array}$ & 0.9 & $\begin{array}{l}\text { Wellness concerns: } \\
\text { Stress }\end{array}$ \\
\hline
\end{tabular}

\begin{tabular}{|c|c|c|}
\hline NEW CASE & & SAMPLE CASE 2 \\
\hline Age: $\mathbf{2 7}$ & $4--1$ & Age: 27 \\
\hline Sex: Male & & Sex: Female \\
\hline $\begin{array}{r}\text { Health Status: High } \\
\text { blood pressure, } \\
\text { Depression }\end{array}$ & 0.7 & Health Status: Insomnia \\
\hline $\begin{array}{r}\text { Personal lifestyle: Ability } \\
\text { to relax (poor), Smoke } \\
\text { (often), Stress level } \\
\text { (Work 10) }\end{array}$ & 0.6 & $\begin{array}{l}\text { Personal lifestyle: } \\
\text { Average sleeping hours } \\
\text { (3), Alcohol (often) }\end{array}$ \\
\hline $\begin{array}{l}\text { Wellness concerns: } \\
\text { Stress, Anxiety }\end{array}$ & 0.7 & $\begin{array}{l}\text { Wellness concerns: } \\
\text { Fatigue }\end{array}$ \\
\hline NEW CASE & & SAMPLE CASE 3 \\
\hline Age: $\mathbf{2 7}$ & & Age: $\mathbf{3 5}$ \\
\hline Sex: Male & & Sex: Female \\
\hline $\begin{array}{r}\text { Health Status: High } \\
\text { blood pressure, } \\
\text { Depression }\end{array}$ & 0.9 & $\begin{array}{l}\text { Health Status: High } \\
\text { Blood Pressure }\end{array}$ \\
\hline $\begin{array}{r}\text { Personal lifestyle: Ability } \\
\text { to relax (poor), Smoke } \\
\text { (often), Stress level } \\
\text { (Work 10) }\end{array}$ & 0.2 & $\begin{array}{l}\text { Personal lifestyle: Skin } \\
\text { Type (Dry), Exercise } \\
\text { (Never) }\end{array}$ \\
\hline $\begin{array}{l}\text { Wellness concerns: } \\
\text { Stress, Anxiety }\end{array}$ & 0 & $\begin{array}{l}\text { Wellness concerns: Dry } \\
\text { Body (Arm, Back, } \\
\text { Chest) }\end{array}$ \\
\hline
\end{tabular}

Fig. 5. Comparison of new case with Sample Cases 1, 2 and 3

\section{Similarity (New Case, Sample Case 1)}

$$
\begin{aligned}
& =1 / 17 *[(1 * 0.8)+(1 * 1.0)+(5 * 0.9)+(5 * 0.9)+(5 * 0.9)] \\
& =1 / 17 *(0.6+1.0+4.5+4.5+4.5) \\
& =\mathbf{0 . 8 9}
\end{aligned}
$$

Similarity (New Case, Sample Case 2)

$$
\begin{aligned}
& =1 / 17 *[(1 * 1.0)+(1 * 0)+(5 * 0.7)+(5 * 0.6)+(5 * 0.7)] \\
& =1 / 17 *(1.0+0+3.5+3.0+3.5) \\
& =0.65
\end{aligned}
$$

$$
\begin{aligned}
& \text { Similarity (New Case, Sample Case } 3) \\
& =1 / 17 *\left[(1 * 0.8)+(1 * 0)+\left(5^{*} 0.9\right)+(5 * 0.2)+(5 * 0)\right] \\
& =1 / 17 *(0.8+0+4.5+1.0+0) \\
& =0.37
\end{aligned}
$$

The results of the similarity computation determine the most-similar case, whose solution will be adopted as the solution to the new case. Based on the similarity calculations above, the system will choose Sample 1 as the solution for the new case $(0.89>0.65>0.37)$. Note that in this simulation, only selection of attributes is considered; in the actual system, other features such as previous wellness record would also be considered. Fig. 6 shows the wellness therapy proposed by the recommender system after analysing the new case. The system has returned a solution with a match of $89 \%$, as computed above.

The recommendation shows that the user may choose from six types of wellness therapy treatment, which have been grouped into three categories of massage, reflexology and fitness therapies.

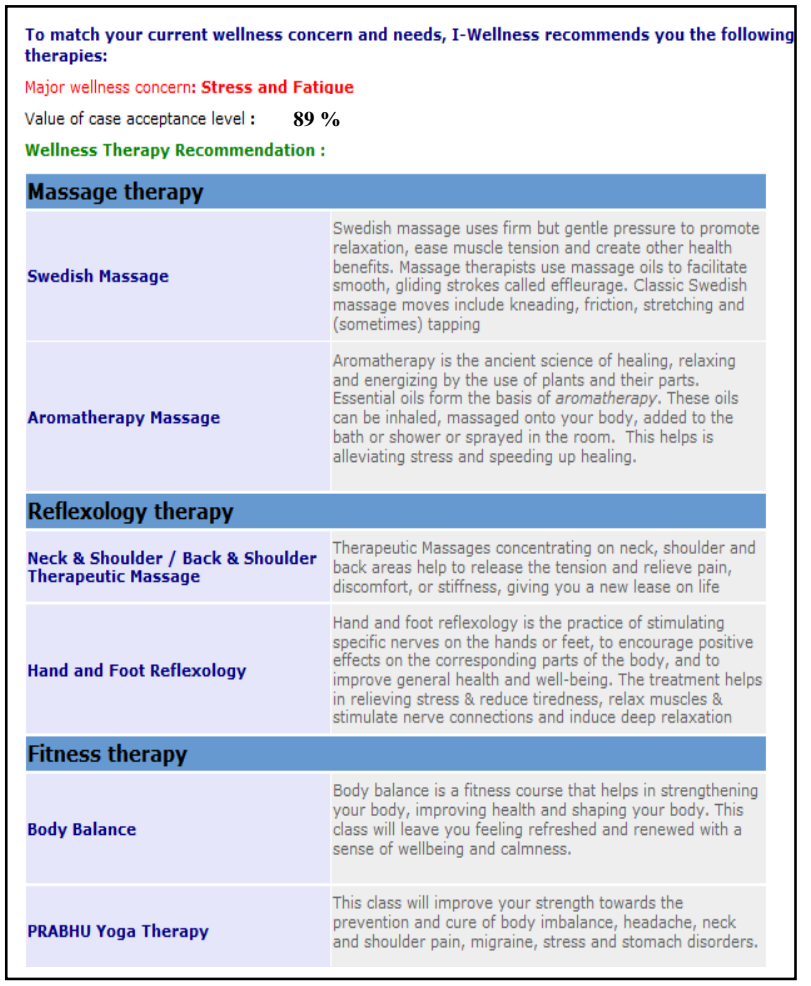

Fig. 6. Results computed from the wellness recommender system

\section{Evaluation of wellness recommender system}

At the end of the study an evaluation survey was carried out to verify the accuracy of the recommendations proposed for the new case in the simulation. In the evaluation phase, a Likert scale was used to measure the responses from wellness consultants and therapists regarding the prototype's wellness therapy recommendations. A sample size of 40 respondents, 
10 from each of four wellness categories (namely, spa and relaxation, reflexology, beauty and slimming and fitness), were randomly selected to answer a simple questionnaire. Completed questionnaires were collected for further analysis.

In the questionnaire, wellness consultants and therapists were asked to express their agreement or disagreement with the wellness recommendations proposed by the prototype for the new case. Rowe and Wright [39] stated that "sensible questions are only sensible if they relate to the domain of knowledge of the specific experts". Therefore, wellness consultants and therapists are the right people to verify the reliability of the proposed wellness recommender system. First, solutions for Sample Cases 1, 2 and 3 were provided by the wellness experts.

These solutions were then compared and applied to those proposed by the prototype for the new case problem. Table 2 shows the descriptive analysis of the evaluation results for Sample Case 1 solutions adapted for the new problem while Table 3 and Table 4 show the analysis of evaluation results for Sample Case 2 and 3 solutions respectively adapted for the new problem.

TABLE II. DESCRIPTIVE ANALYSIS Of EVAluation Results (SOLUTION For NEW CASE B ASED ON SOLUTIONS IN SAMPLE CASE 1)

\begin{tabular}{|l|c|c|}
\hline \multicolumn{1}{|c|}{ Wellness therapy } & Mean & $\begin{array}{c}\text { Standard } \\
\text { Deviation }\end{array}$ \\
\hline Swedish massage & 4.1 & 0.568 \\
\hline Aromatherapy Massage & 4.0 & 0.667 \\
\hline Hand and foot reflexology & 4.0 & 0.816 \\
\hline Body Balance & 4.0 & 0.471 \\
\hline $\begin{array}{l}\text { Neck \& shoulder / Back \& shoulder } \\
\text { Therapeutic Massage }\end{array}$ & 3.7 & 0.675 \\
\hline PRABHU Yoga & 3.7 & 0.675 \\
\hline Body scrub \& massage & 3.1 & 0.316 \\
\hline Swedish Delight & 2.8 & 0.422 \\
\hline
\end{tabular}

TABLE III. DESCRIPTIVE ANALYSIS OF EVALUATION RESULTS (SOlution For New CASE BASEd On SOlutions In SAMPle CASE 2)

\begin{tabular}{|l|c|c|}
\hline \multicolumn{1}{|c|}{ Wellness therapy } & Mean & $\begin{array}{c}\text { Standard } \\
\text { Deviation }\end{array}$ \\
\hline Hand \& foot reflexology & 4.0 & 0.816 \\
\hline Foot reflexology & 3.5 & 0.527 \\
\hline Head, shoulder \& back massage & 2.7 & 0.483 \\
\hline Body scrub and massage & 2.6 & 0.516 \\
\hline Aerobic & 2.6 & 0.516 \\
\hline Basic yoga & 2.6 & 0.516 \\
\hline Malay traditional massage & 2.4 & 0.516 \\
\hline
\end{tabular}

TABLE IV. DESCRIPTIVE ANALYSIS OF EVALUATION RESULTS (SOLUTION For NEW CASE BASEd ON SOLUTIONS IN SAMPLE CASE 3)

\begin{tabular}{|l|c|c|}
\hline \multicolumn{1}{|c|}{ Wellness therapy } & Mean & $\begin{array}{c}\text { Standard } \\
\text { Deviation }\end{array}$ \\
\hline Traditional Massage & 2.0 & 0.471 \\
\hline Traditional papaya facial & 1.8 & 0.422 \\
\hline Silky body treatment & 1.3 & 0.483 \\
\hline Body Nourishing & 1.3 & 0.483 \\
\hline Steam bath & 1.2 & 0.422 \\
\hline
\end{tabular}

From the descriptive analysis, we can see that most of the mean in Table 2 is above 3.0. The rating result from evaluation is higher than the Likert five-point average (average=3.0). By referring to Fig. 6 above, we see that the level of acceptance in comparing the new case with sample case 1 is $89 \%$. This means that there is an $89 \%$ chance that the solution in sample case 1 can be adapted to solve the problem posed in the new case. However, wellness consultants from beauty and slimming disagreed with Swedish Delight therapy as a solution in the new case. This indicates that a higher level of acceptance is needed in order to propose accurate solutions for problems in the beauty and slimming category.

On the other hand, most of the mean in Table 3 is below 3.0. The rating result from evaluation here is lower than the Likert five-point average (average=3.0). Referring to the similarity calculation, we can see that the level of acceptance in comparing the new case with sample case 2 is $65 \%$. This means that the solution for sample case 2 is not appropriate for solving the problem posed in the new case. However, wellness consultants in the area of reflexology agreed that similar cases can be used even though the level of acceptance is $65 \%$.

In Table 4, most of the mean is below 2.0. This indicates that wellness consultants agree that the solution in sample case 3 cannot be used to solve the problem posed in the new case. This is confirmed by the low similarity calculation of the new case with sample case 2 , which is only $37 \%$.

\section{CONCLUSION}

This study proposed that online wellness consultation can be carried out using HCBR in a wellness recommender system. The purpose of employing HCBR in wellness recommendation is to capture experts' knowledge and experience together with previously resolved wellness cases in a case database. Users present their wellness concerns, which are solved by locating an identical or similar case in the case database (CBR). If the case database contains no sufficiently similar cases, the system will recommend a suitable wellness solution by using predetermined standard rules (RBR).

The present study concentrated on non-medical wellness therapies that fall into five disciplines, namely: spa and relaxation, reflexology, beauty and slimming, skin and body care, and fitness. Future work should focus on the study of medical wellness recommendation, such as acupuncture, antiaging, medical massage and other therapies, in order to provide a holistic solution in the wellness market. In conclusion, HCBR can be effectively applied in an online wellness recommender system to match a user's current wellness concerns with suitable wellness therapies.

\section{ACKNOWLEDGMENT}

The authors would like to thank the Universiti Sains Malaysia, Penang for supporting this study.

\section{REFERENCES}

[1] Omar, A., Wahlqvist, M. L., Kouris-Blazos, A., \& Vicziany, M., "Wellness management through Web-based programmes," (2005) Journal of Telemedicine and Telecare, vol. 11 (1), pp. 8-11.

[2] Stahl, V., "Wellness and sustainability," (2010) [internet] Available at http://www.cognis.com/NR/rdonlyres/3BE09E03-8E04-49FD-B56FE1E8EB6D7A85/0/05_CC_Worldwidetrends_e_Sept07_ffcf.pdf [Accessed 21 August 2012]. 
[3] Grandinetti, D.A., "Doctors and the web: Help your patients surf the Net safely," (2000) Medical Economics, vol. 77 (5), pp. 186.

[4] Susan, D., "Ramifications of web-based health assessment tools on consumer behaviours and health outcomes," (2010) Available at: http://susandorfman.com/uploads/DHA_Dissertation_susan_dorfman_fe b_27_2010_Final.pdf [Accessed 21 August 2012].

[5] Impicciatore, P., Pandolfini, C., Casella, N., \& Bonati, M., "Reliability of health information for the public on the World Wide Web: systematic survey of advice on managing fever in children at home," (1997) BMJ, 314 (1875).

[6] Purcell, G. P., Wilson, P., \& Delamothe, T., "The Quality of health information on the Internet," (2002) BMJ, 324.

[7] Eysenbach, G., \& Thomson, M., "The FA4CT Algorithm: A New Model and Tool for Consumers to Assess and Filter Health information on the Internet," (2007) Kuhn K (ed.) Medinfo 2007 Proceedings (in press) [Internet] Available https://tspace.library.utoronto.ca/handle/1807/9795 [Accessed 10 March 2013].

[8] Beller, S., "Information overload and Health Decision-Making (Part 1)," (2006) [Internet] Available at: http://curinghealthcare.blogspot.com/2006/09/information-overload-andhealth.html [Accessed 11 March 2013].

[9] Fitness Wellness Guide, "Fitness Wellness Disclaimer," (2008) [Internet] Available at: http://www.fitness-wellnessguide.com/disclaimer.html [Accessed 10 March 2013].

[10] Whitaker Wellness Institute, "Disclaimer," (2009) [Internet]. Available at: http://www.whitakerwellness.com/about-us/disclaimer/ [Accessed 10 March 2013].

[11] Wellness Layer, "DietWatch Personal Terms of Use," (2009) [Internet] Available http://www.dietwatch.com/dietwatch/shared/about_us.asp?view=Terms $\% 20$ of\%20Use [Accessed 10 March 2013].

[12] Long, F., Zhang, Y., \& Hu, F., "A Personalised Recommender System Framework based on Ontology and Bayesian Network in E-commerce," (2011) Advanced Materials Research, vol. 143-144, pp. 961-965.

[13] Chen, S., "An Electronic Commerce Recommender System Based on Product Character," (2011) Advanced Materials Research, vol. 267, pp. 909-912.

[14] Burke, R., "Knowledge-based recommender systems," (2000) Encyclopaedia of Library and Information Science.

[15] Kim, H-N., et al., "Collaborative user modelling for enhanced content filtering in recommender systems," (2011) Decision Support Systems, doi:10.1016/j.dss.2011.01.012.

[16] Maidel, V., Shoval, P., Shapira, B., \& Maimon, M., "Ontological content-based filtering for personalised newspapers," (2010) Online Information Review, vol. 34, No. 5, pp. 729-756.

[17] Desrosiers, C., \& Karypis, G., "A Comprehensive Survey of Neighbourhood-based Recommendation Methods," (2011) Recommender Systems Handbook Part 1, pp. 107-144.

[18] Meteren, R. V., \& Someren, M. V., "Using content-based filtering for recommendation," (2000) [Internet] Available at: http://www.ics.forth.gr/ potamias/mlnia/paper_6.pdf [Accessed 13 March 2013].

[19] Cai, X., et al., "Collaborative filtering for people to people recommendation in social networks," (2010) Advances in Artificial Intelligence, vol. 6464, pp. 476-485.

[20] Sarwar, B. M., Karypis, G., Konstan, J. A., \& Riedl, J. T., "Application of Dimensionality Reduction in Recommender System - A Case Study," (2000) [Internet] Available at: http://robotics.stanford.edu/ ronnyk/WEBKDD2000/papers/sarwar.pdf [Accessed 13 February 2013].

[21] Smyth, B., \& Cotter, P., "A Personalized Television Listings Service," (2000) Communication of the ACM, vol. 43 (8).
[22] McCarthy, J., "What is Artificial Intelligence?" (2007) [Online] Stanford University Available at: http://wwwformal.stanford.edu/jmc/whatisai/whatisai.html [Accessed 11 February 2013].

[23] Luger, G. F., “Artificial Intelligence,” (2002) Fourth Edition. AddisonWesley, Pearson Education.

[24] Abu-Naser, S.S., El-Hissi, H., \& El-khozondar, N., "An expert system for endocrine diagnosis and treatments using JESS," (2010) Journal of Artificial Intelligence, vol. 3(4) pp. 239-251.

[25] Eshach, H., \& Bitterman, H., "From Case-based Reasoning to Problembased Learning," (2003) Academic Medicine, vol. 78 (5).

[26] Wang, W. M., Cheung, C. F., Lee, W. B., \& Kwok, S. K., "Knowledgebased treatment planning for adolescent early intervention of mental healthcare: a hybrid case-based reasoning approach," (2007) The Journal of Knowledge Engineering, vol. 24 (4), pp. 232-251.

[27] Lim, T. P., "I-Wellness: Application of hybrid case-based reasoning for wellness therapy recommendation in wellness community portal," (2010) Universiti Sains Malaysia.

[28] Lee, M. R., "An exception handling of rule-based reasoning using casebased reasoning," (2002) Journal of intelligent and Robotic System, Vol. 35, pp. 327-338.

[29] Lim, T.P., \& Husain, W., "I-Wellness: A hybrid Case-based Framework for personalised wellness therapy," (2010) Proceeding of International Symposium on Information Technology 2010 (ITSIM'10), vol. 3, pp. 1193-1198.

[30] Jaglan, V., Dalal, S., \& Srinivasan, S., "Improving performance of business intelligence through case based reasoning," (2011), International Journal of Engineering Science and Technology (IJEST), vol. 3, No. 4.

[31] Branden, M., Wiratunga, N., Burton, D., \& Craw, S., "Integrating casebased reasoning with an electronic patient record system," (2011), Artificial Intelligence in Medicine, vol. 51 (2), pp. 117-123.

[32] Schmidt, R., \& Gierl, L., "Case-based reasoning for antibiotics therapy advice: an investigation of retrieval algorithms and prototypes," (2001) Artificial Intelligence in Medicine, Vol. 23 (2), pp. 171-186.

[33] Lim, T.P., \& Husain, W., "Integrating knowledge-based system in Wellness Community Portal," (2010) Proceeding of International Conference on Scientific \& Social Science Research (CSSR 2010). [Internet] Available http://ieeexplore.ieee.org/xpl/freeabs_all.jsp?arnumber=5773798 [Accessed 21 August 2013].

[34] Golding, A. R., \& Rosenbloom, P. S., "Improving Rule-Based Systems through Case-Based Reasoning," (1991) In Proceedings of AAAI, Anaheim, CA, pp. 22-27.

[35] Chan, F. T. S., "Application of a hybrid case-based reasoning approach in electroplating industry," (2005) Expert Systems with Application, vol. 29, pp. 121-130.

[36] Lim, T.P., \& Husain, W., "The Development of Personalized Wellness Therapy Recommender System Using Hybrid Case-Based Reasoning," (2010) Proceeding of 2nd International Conference on Computer Technology and Development (ICCTD 2010). Available at: http://ieeexplore.ieee.org/xpl/freeabs_all.jsp?arnumber $=5646071$ [Accessed 22 August 2013].

[37] Ravana, S. D., Abdul Rahman, S. S., \& Chan, H. Y., "Web-Based Diet Information System with Case-Based Reasoning Capabilities," (2006) International Journal of Web information Systems, vol 2 (3/4), pp. 154163.

[38] Burke, R., "Hybrid Recommender Systems: Survey and Experiments," (2002) User Modelling and User-Adapted Interaction, vol. 12, pp. 331370.

[39] Rowe, G., \& Wright, G.., "The Delphi techniques as a forecasting tool: issues and analysis," (1999) International Journal of Forecasting, 15, pp. 353-375 